\title{
Strategic imperatives and core competencies to empower small and medium enterprises
}

\author{
Fahim Akhter*
}

Department of Management Information Systems, College of Business Administration, King Saud University, Riyadh, Saudi Arabia

\section{A RT ICLE INFO}

\section{Article history:}

Received 22 January 2017

Received in revised form

4 April 2017

Accepted 5 April 2017

\section{Keywords:}

SMEs

Entrepreneurs

Hermeneutic

Information

Systems

Saudi Arabia

\begin{abstract}
A B S T R A C T
This empirical study argues that the time is ripe for the commercial banks, non-profit microfinance organizations and venture capitalists to seek out initiatives to step up their efforts to serve small and medium enterprises (SMEs) in Saudi Arabia. The collapse and dependency exacerbate the sustainability of the SMEs on of oil prices in Saudi Arabia. This empirical study has taken to address the growth opportunities, challenges, and strategic options that hampered the sustainability and evolution of SMEs in Saudi Arabia. The researcher conducted twenty-one focus interviews with Saudi entrepreneurs to learn about the challenges and the impact of objectivity and correctness of initiatives to SMEs sustainability and growth The study used the hermeneutic technique, to analyze the transcriptions of the recorded interviews, which employs a part-to-whole mode of interpretation. This method helped the researcher to understand the entrepreneur's view and put aside his assumptions about a situation or experience. The themes that surfaced from the twenty-one interviews; financial support \& partnerships, labor laws and best practices, and technologically integrated business model.
\end{abstract}

(C) 2017 The Authors. Published by IASE. This is an open access article under the CC BY-NC-ND license (http://creativecommons.org/licenses/by-nc-nd/4.0/).

\section{Introduction}

The International Finance Corporation (IFC) has reported that besides relying heavily on oil, the country has $1.8 \mathrm{~m}$ SMEs in Saudi Arabia that comprised $90 \%$ of all the business enterprises. The lending to SMEs as a share of total credit for about 1.7 percent in Saudi Arabia, while in Jordan, Lebanon, Morocco and Yemen it is 13, 16, 20 and 24 percent respectively. Several reasons add up to the low level of SMEs lending in Saudi Arabia, including limited bank risk appetite, lack of local employment, incapability of financial institutes to modify business models and the lack of reliable credit history or correct financial statements of SMEs. These challenges force the financial institutions to require high collateral requirements and sometimes have lengthy loan processes, which become an impediment to financing (Al-Kibsi et al., 2015).

The criteria to be qualified as SMEs are subject to debate in different countries. For example, in Saudi Arabia, the small business supposed to have fewer

\footnotetext{
* Corresponding Author.

Email Address: fakhter@ksu.edu.sa

https://doi.org/10.21833/ijaas.2017.04.025

2313-626X/C 2017 The Authors. Published by IASE.

This is an open access article under the CC BY-NC-ND license

(http://creativecommons.org/licenses/by-nc-nd/4.0/)
}

than 60 employees and has less than $\$ 1.3 \mathrm{~m}$ in assets, while a medium company employs fewer than 100 employees and has access to between $\$ 1.3 \mathrm{~m}$ and $\$ 5.3 \mathrm{~m}$. The Saudi banks define SMEs as a business with an annual turnover of up to $\$ 8 \mathrm{~m}$. The European Commission represents the SMEs that employs fewer than ten workers and has a turnover of less $€ 2 \mathrm{~m}$, while a small business has fewer than 100 staff with a turnover of less than $€ 10 \mathrm{~m}$, and a medium-sized enterprise has a workforce smaller than 250 and an annual turnover of less than $€ 50 \mathrm{~m}$ (OBG, 2017).

\section{Literature review}

This research has referred literature and conducted interviews to address the opportunities, challenges, and barriers to the sustainability and evolution of SMEs. The current practices and optimistic reforms have learned through twenty-one interviews, conducted individually with owners of SMEs in Riyadh, Saudi Arabia.

Previous research by the Oxford Business Group (OBG, 2017) has done on SMEs, in Saudi Arabia to look into the challenges faced by SMEs, including financial constraints and lack of local employment. This research has addressed the necessary supports provided by developing countries to SMEs sector to promote diversification, innovation, and jobs. 
Contrary, Saudi Arabia's reliance on oil has outweighed the necessity of SMEs in the past. The government has taken drastic actions to support other industries to minimize dependency on the oil sector by introducing long-term reforms such as abolishing ministries and introducing new channels to accumulate revenue.

The Saudi government recognizes to benefit from growth in the SMEs segment as a major contributor to GDP and employment. Furthermore, SMEs is increasingly attracting government attention as a source of economic growth, especially in the prevailing economic climate and a strategic move to minimize dependency on the oil sector. In this respect, King Salman has outlined strategies by emphasizing the role of SMEs in the Kingdom's 2030 development plan. Currently, the SMEs are insufficiently contributing 33\% to the Saudi gross domestic product as compare to the US (50\%), France (56\%), Spain (57\%) and Japan (64\%). The government's initiatives to sustain SMEs are reinforced by the Saudi International Finance Corporation (IFC) by excluding unnecessary requirements to access the credit resources by SMEs. In this regard, the government has supported the financial institutes, including Riyadh, Saudi Hollandi, and Al Rajhi banks to accommodate SMEs financial needs. The local banks have initiated many steps to provide necessary logistics, for example, Riyadh Bank is offering managerial and accounting expertise to train SMEs clients. Similarly, Samba Financial Group is hosting workshops for SMEs through its Business Edge program. These types of initiatives to SMEs are strengthening their existence and allow them to compete for more financial resources.

\section{Methodology}

This research combines several different sources of information and ideas, including an extensive interview with 21 Saudi entrepreneurs. These interviews provided insights into how banks perceive the SMEs opportunity, governments planning, and initiatives to support SMEs and challenge SMEs to face in setting-up and running the business. The study uses focus interviews, qualitative method to ensure the objectivity and correctness of research results. The researcher used the 'hermeneutic technique' (Kvale, 1983), to analyze the transcriptions of the recorded interviews, which employs a part-to-whole mode of interpretation (Thompson et al., 1989). This method helped the researcher to understand the respondent's view and put aside his assumptions about a situation or experience. The hermeneutic technique is a clarification process by which scientists attempt to understand the respondents' viewpoints by analyzing different parts of the text. After the completion of each interview, a new partto-whole phase begins in which separate meetings to each other and shared patterns identified. These patterns of commonalities referred to as global themes (Kvale, 1983).
During the interview sessions, the researcher was present to explain the topic and clarify any concern that arose from the participants. The questions used by the researcher followed the course of the dialogue and aimed at developing descriptions of the respondents' business experiences. The interviewer used descriptive questions such as "How was your business experience in Saudi Arabia?", "How did you feel or experience while setting up the SME...?", and uses the respondent's words and phrases to follow up. For example, if a participant said, "We had limited access to finical resources that were available from the government," an appropriate follow-up question might be "Did you approach the Ministry of Finance for the support?" The interviews were audiotaped to free the researcher from taking notes so he could ensure that the interview process went smoothly, knowing the data could always be retrieved later. Participants also told that they would be able to receive a copy of the report containing the results and findings of the study should they wish. Participation was voluntary, and no compensation offered for the interviews, which lasted 1-2 hours each. Each meeting began with open-ended questions in English posed in a way to encourage the respondent to develop dialogue resembling a conversation, with the interviewer providing the context from which the respondents' descriptions of challenges and barriers that are faced by SMEs could flow freely and in detail. Participants were thus encouraged to discuss not only their entrepreneurship experiences but also their business attitudes and typical ways of addressing the concerns and challenges. The themes that surfaced from the twenty-one interviews; adoption of information systems to facilitate the integration of business processes, the limited pool of affordable employees, labor laws and best practices and financial support from local banks to support and foster SMEs.

This research has collected different opinions through interacting and communicating with experts. The process has produced benefits of consensus after selecting, ensuring, and modifying expert's opinions, comments and suggestions. The process leads the research to define the problems, confirm sampling structure, formulate an interview outline, recruit sample, explain and analyze data, write reports and make decisions (Chien et al., 2016; Ryan et al., 2014). The following challenges and reforms discussed in this study are to harvest the potential benefits of SMEs.

\section{Strategic imperative}

The Saudi government is committed to providing needed financial support for the growth of SMEs by encouraging banks to sanction loans to them. Furthermore, the Saudi Industrial Development Fund (SIDF) has introduced the kafalah scheme to prioritize and strengthen the banks' confidence towards SMEs by ensuring $80 \%$ of loan sanctions to SMEs. The Kafalah scheme will leverage banks to 
consider SMEs as a potential market for investment and consider them as one of the strategic stakeholders. The government financial assurance has mitigated the banks' risk when SMEs becomes a defaulter or ran into financial troubles. The scheme is similar like offered by the Federal Deposit Insurance Corporation (FDIC) in the United States of America.

\section{Challenges to SMEs}

A Saudi government has taken many steps to address the challenges and barriers faced by SMEs, including lack of available financial resources, redundant laws and false perception of Saudi entrepreneurs towards job security. These obstacles have also validated by the survey conducted by the Riyadh Chamber of Commerce and Industry, that stated, $65 \%$ respondents believe that bureaucracy is one the substantial barrier, followed by rutted access to finance (59\%) and workforce (44\%) issues (OBG, 2017). In Saudi Arabia, 47\% of SMEs populated in the commercial and hotel sectors, in addition to $27 \%$ in construction, $12 \%$ in industry, $6 \%$ in social services and $8 \%$ in other areas.

It has observed from the research (OBG, 2017) that local workforce prefers to join a business sector due to the perception of job instability, long working days, lower salaries and less attractive perks in the industry. This recruitment predicament forced SMEs to employ expatriate that causes delay and substantial financial losses. The statistics (OBG, 2017) revealed that more than $65 \%$ of Saudi employees consumed by the state, while $87 \%$ of the private sector workforce employed from the local expatriate. The following factors also influence the SEMs fair recruitment process, including Saudization policies, which enforced quota system.

The respondents have revealed in the interviews that lack adoption and implementation of technology, especially not adopting information systems, is hurting the growth of SMEs. It is extremely critical for SMEs to grow or elevate their competitiveness by utilizing information systems. The technological advantage will reduce costs, increase customer satisfaction, and improve business processes (HassabElnaby et al., 2012; Chatzoglou et al., 2016).

\section{Strategic reforms}

The government has to minimize the surplus of needless regulations and procedures that add to the costs of setting-up and running the business. These preventable regulations and practices cause the delays to perform business activities and force SMEs towards the costly solutions from third parties. These avoidable obstacles hurt the growth and economy of the SMEs and blocked their local and international partnerships and disconnect them from the global market.

\subsection{Financial support and partnerships}

The government is strengthening the SEMs sector by promoting and exchanging business know-how among other countries. It announced a deal to foster cooperation in the SMEs sector at the end of the 14th Saudi Arabia-Japan Business Council meeting in Tokyo (Tago, 2014). The Arab News reported (Chien et al., 2016) that 200 Saudis and Japanese businesspeople discussed multilateral cooperation in training, industry and advanced technologies. It has been decided in the meeting to promote bilateral visits for Saudi and Japanese entrepreneurs and business leader. The government has taken numerous initiatives to encourage local banks and entrepreneurs to support and foster SMEs. In the light of the regulatory actions and support, banks must manage risk innovatively such as through psychometric testing, cash flow estimates, or qualitative credit assessment.

A respondent has suggested during the interview that banking credit process, including loan origination, monitoring and collections must be streamlined. He has suggested that banks must lead from the front to educate and empower SMEs clients. He shared that many entrepreneurs do not understand how the bankers made decisions on the loan applications. The financial and business illiteracy causes SMEs clients to present incomplete or inadequate business cases to request start-up packages. Banks should educate the entrepreneurs on how they operate and made decisions through seminars or personal meetings. Furthermore, banks should team up with the government to overcome challenging business through establishing risksharing facilities and commercial credit bureaus. Furthermore, banks should also offer to customize privilege financial packages to under-served and unserved SMEs.

\subsection{Labor laws and best practices}

The local regulations of the Ministry of Labor are required to be more transparent in respect of the recruitment process, for example, SMEs should also have equal access to the local workforce as compared to Corporate. In many cases, SMEs are forced to outsource human resources from foreign labor markets that cause a delay in recruitment process due to the slow visa process. The respondents have suggested that high costs of running SMEs and the lack of facilitation of trade have ensured that Saudi entrepreneurial spirit is denied its rightful place in the global business arena. It also pointed out from a respondent to simplify the flood of local regulations and procedures that add to costs, lead to delays, and warrant the services of third parties in compliance with the legal proceedings. These overheads and unnecessary business procedures discourage many SMEs from even considering connecting with global markets. At one of the solutions of this barrier is suggested by the respondent is by creating a one-stop window to 
address general legal business procedures. This onestop window would provide all the required governmental assistance on the premises and will also eliminate the discretion of officials to cause delays. On the same challenge, another suggestion made by another respondent that by easing the transaction costs imposed by different ministries, including industrial licensing, cross-border procedures and so forth will enhance the growth and sustainability of the SMEs. The reduced costs of managing SMEs in Saudi Arabia would attract global entrepreneurs to look at Saudi as a hub of their business for their global distribution networks.

\subsection{Technological integrated business model}

It has suggested during the interviews that the SMEs must adopt and integrate information systems to facilitate the business processes across functional units, using a standard database and shared information. The technological reform is also supported by previous studies (Chatzoglou et al., 2016) by stating that information technology will enable the decision-making process to be timely, consistent and reliable across organizational units and geographical locations. The respondents believe the globally adopted business model is evolving around the adoption of electronic commerce (Fahim, 2016). Researchers (Fahim and Wafi, 2016) have suggested that there are several barriers besides security and privacy, which deter to conduct business electronically. Also, local norms of doing business include consumer resources, age, knowledge, lifestyle, educational level, attitude, motivation, marital status, personality, values, and cultural values, could have weights in influencing a consumer's buying decision. For example, the attitude of consumers towards online shopping in developed countries such as the UK or the U.S. may be different from users from less developed countries such as Pakistan, Bangladesh, United Arab Emirates and Saudi Arabia.

\section{Conclusion}

The interview outcome argues that the time is right for the commercial banks, non-profit microfinance organizations and venture capitalists to seek out initiatives and step up their efforts to serve SMEs in Saudi Arabia. The positive outcome has supported and witnessed that global banks in emerging markets are finding ways to overcome the difficulties of serving the important SMEs segment. Respondents believe that local banks can facilitate strategic plans through innovations in technology, risk assessment, and improved business models. Most of the interviewees believe these practices are complementary and remedies for the obstacles of serving SMEs clients, including low revenue per customer, high risk of credit losses and the need for a physical presence to lend.

A government is keen to overhauled and invest in the financial sector so it can leverage more money effectively to SMEs. A government is encouraging SEMs to play a bigger role in the manufacturing and services sectors besides construction industry to create job opportunities for young Saudis. The government initiatives will strengthen and help the Saudi economy to achieve sustainable growth by 2030. Fundamental reforms will also be needed, including overhauling the current business model of investment, offered attractive business terms and conditions and clear human resources laws in place. All the twenty-one entrepreneurs who interviewed believed there is an exciting opportunity for commercial banks, non-profit microfinance organizations and venture capitalists and others achieve a step change in their approach to Saudi SMEs, in light of several factors that presented in this study.

\section{Acknowledgement}

The author extends his appreciation to the Deanship of Scientific Research at King Saud University, represented by the Research Centre at the College of Business Administration, for funding this research.

\section{References}

Al-Kibsi G, Woetzel J, Isherwood T, Khan J, Mischke J, and Noura H (2015). Saudi Arabia Beyond: The Investment and Productivity Transformation. McKinsey Global Institute, New York, USA. Available online at: http://www.mckinsey.com/global-themes/employment-andgrowth/moving-saudi-arabias-economy-beyond-oil

Chatzoglou P, Fragidis L, Chatzoudes D, and Symeonidis S (2016). Critical success factors for ERP implementation in SMEs. In the Federated Conference on Computer Science and Information Systems, IEEE, Gdansk, Poland: 1243-1252.

Chien TK, Lai WL, Hou JY, and Chang HL (2016). A study on the structure design of SMEs' franchiser mechanism. In the $5^{\text {th }}$ IIAI International Conference on Advanced Applied Informatics, IEEE, Kumamoto, Japan: 730-734. https://doi.org/10.1109/IIAI-AAI.2016.161

Fahim A (2016). Cultural dimensions of behaviors towards ECommerce in a developing country context. International Journal of Advanced Computer Science and Applications, 7(4): 100-103

Fahim A and Wafi A (2016). Online trust and young entrepreneurs: A case study of saudi arabia. International Journal of Theoretical and Applied Information Technology, 86(1): 10-17.

HassabElnaby HR, Hwang W, and Vonderembse MA (2012). The impact of ERP implementation on organizational capabilities and firm performance. Benchmarking: An International Journal, 19(4/5): 618-633.

Kvale S (1983). The qualitative research interview: A phenomenological and a hermeneutical mode of understanding. Journal of Phenomenological Psychology, 14(2): 171-196.

OBG (2017). Starting small: Given the large number of local SMEs, opening up financing and opportunities is key. Oxford Business Group, London, UK. Available online at: https://www.oxfordbusinessgroup.com/analysis/startingsmall-given-large-number-local-smes-opening-financing-andopportunities-key-2 
Ryan KE, Gandha T, Culbertson MJ, and Carlson C (2014). Focus group evidence implications for design and analysis. American Journal of Evaluation, 35(3): 328-345.

Tago, AH (2014). Saudi-Japan business Council discusses technology cooperation. Arab News. Available online at: http://www.arabnews.com/news/527741
Thompson CJ, Locander WB, and Pollio HR (1989). Putting consumer experience back into consumer research: The philosophy and method of existential phenomenology. Journal of Consumer Research, 16(2): 133-146. 